\title{
Fine mapping and epistatic interactions of the vernalization gene $V R N-D 4$ in hexaploid wheat
}

\author{
Nestor Kippes · Jie Zhu • Andrew Chen $\cdot$ Leonardo Vanzetti $\cdot$ \\ Adam Lukaszewski $\cdot$ Hidetaka Nishida $\cdot$ Kenji Kato $\cdot$ \\ Jan Dvorak · Jorge Dubcovsky
}

Received: 29 August 2013 / Accepted: 17 October 2013 / Published online: 9 November 2013

(C) The Author(s) 2013. This article is published with open access at Springerlink.com

\begin{abstract}
Wheat vernalization requirement is mainly controlled by the VRN1, VRN2, VRN3, and VRN4 genes. The first three have been cloned and have homoeologs in all three genomes. VRN4 has been found only in the $\mathrm{D}$ genome $(V R N-D 4)$ and has not been cloned. We constructed a highdensity genetic map of the $V R N-D 4$ region and mapped $V R N-D 4$ within a $0.09 \mathrm{cM}$ interval in the centromeric region of chromosome 5D. Using telocentric 5D chromosomes generated from the VRN-D4 donor Triple Dirk F,
\end{abstract}

N. Kippes, J. Zhu and A. Chen contributed equally to this work.

Accession numbers: AB846583, AB846584,

AB846585, AB846586, AB846587, AB845597,

AB845598, AB845599, AB845600, AB845601,

AB845602, KF761667, KF761666, KF761670, KF761668

Communicated by S. Hohmann.

Electronic supplementary material The online version of this article (doi:10.1007/s00438-013-0788-y) contains supplementary material, which is available to authorized users.

N. Kippes · A. Chen $\cdot$ J. Dvorak $\cdot$ J. Dubcovsky $(\varangle)$

Department of Plant Sciences, University of California, Davis, CA 95616, USA

e-mail: jdubcovsky@ucdavis.edu

\section{J. Zhu}

USDA-ARS Wheat Genetics, Quality, Physiology and Disease Research Unit, Washington State University, Pullman, WA 99164-6420, USA

\section{Vanzetti}

Grupo de Biotecnología y Rec. Genéticos, INTA EEA Marcos

Juárez, Ruta 12 S/N, (2580), Marcos Juárez, Córdoba, Argentina

L. Vanzetti

Consejo Nacional de Investigaciones Científicas y Técnicas

(CONICET), Buenos Aires, Argentina we determined that $V R N-D 4$ is located on the short arm. The $V R N-D 4$ candidate region is colinear with a $2.24 \mathrm{Mb}$ region on Brachypodium distachyon chromosome 4, which includes 127 predicted genes. Ten of these genes have predicted roles in development but we detected no functional polymorphisms associated to $V R N-D 4$. Two recombination events separated $V R N-D 4$ from TaVIL-DI, the wheat homolog of Arabidopsis vernalization gene VIL1, confirming that this gene is not a candidate for $V R N-D 4$. We detected significant interactions between $V R N-D 4$ and other four genes controlling vernalization requirement (Vrn-A1, Vrn-B1, Vrn-D1, and Vrn-B3), which confirmed that $V R N-D 4$ is part of the vernalization pathway and that it is either upstream or is part of the regulatory feedback loop involving $V R N 1, V R N 2$ and $V R N 3$ genes. The precise mapping of $V R N-D 4$ and the characterization of its interactions with other vernalization genes provide valuable information for the utilization of $V R N-D 4$ in wheat improvement and for our current efforts to clone this vernalization gene.

\author{
A. Lukaszewski \\ Department of Botany and Plant Sciences, University \\ of California, Riverside, CA 92521, USA \\ H. Nishida $\cdot$ K. Kato \\ Graduate School of Environmental and Life Science, Okayama \\ University, 1-1-1, Tsushima-Naka, Kita-Ku, Okayama 700-8530, \\ Japan \\ J. Dubcovsky \\ Howard Hughes Medical Institute and Gordon and Betty Moore \\ Foundation Investigator, Chevy Chase, USA
}


Keywords Wheat - Vernalization $\cdot V R N-D 4 \cdot V R N 1$. Genetic mapping $\cdot V I L \cdot$ Flowering

$\begin{array}{ll}\text { Abbreviations } \\ \text { RT-PCR } & \begin{array}{l}\text { Reverse Transcription Polymerase Chain } \\ \text { Reaction }\end{array} \\ \text { QTL } & \text { Quantitative Trait Loci }\end{array}$

\section{Introduction}

Wheat (Triticum aestivum L.) is the second largest crop in dietary intake and the first in harvested area worldwide (FAO 2012), which makes it a critical resource for world food security. The wide distribution of wheat and its ability to grow in very different environments is attributed in part to the plasticity of the gene network that regulates its reproductive development (Distelfeld et al. 2009a). This plasticity allows wheat to adapt to very different growing conditions and is used by wheat breeders to maximize seed production under different or changing environments.

Photoperiod and temperature are the two main environmental cues used by wheat to adjust its flowering time to seasonal changes. Winter wheats, which are sown in the fall, require a prolonged exposure to cold temperatures (known as "vernalization") to accelerate flowering. The vernalization requirement delays reproductive development, protecting the sensitive reproductive organs from frost damage during the winter.

In wheat and barley, the vernalization requirement is mainly controlled by four genes, VRN1, VRN2, VRN3 and VRN4 (Danyluk et al. 2003; Trevaskis et al. 2003; Yan et al. 2003, 2004a, 2006; Yoshida et al. 2010). The first three vernalization genes have been cloned and the mutations responsible for the loss of the vernalization requirement have been characterized (Yan et al. 2004b, 2006; Fu et al. 2005; von Zitzewitz et al. 2005; Distelfeld et al. 2009b; Nitcher et al. 2013). Homoeologs of VRN1, VRN2, and $V R N 3$ have been identified in the three genomes of hexaploid wheat (A, B and D genomes), but natural variation at the VRN4 locus has been identified only in the $\mathrm{D}$ genome. In wheat, a letter is used before the gene number to indicate the genome and therefore, VRN4 will be referred hereafter as $V R N-D 4$.

VRN1 encodes a MADS-Box transcription factor with high similarity to the meristem-identity gene AP1 in Arabidopsis (Danyluk et al. 2003; Trevaskis et al. 2003; Yan et al. 2003). Natural variation at the VRN1 promoter region or at the first intron is associated with a reduction or elimination of the vernalization requirement and with a relatively rapid upregulation of VRNI transcript levels in both apices and leaves of non-vernalized plants (Yan et al. 2004b; Fu et al. 2005). VRN1 null mutants have a very late flowering but still produce normal flowers and fertile seeds (Chen and Dubcovsky 2012). The main function of the upregulation of $V R N 1$ in the leaves in the spring is to downregulate VRN2 (Chen and Dubcovsky 2012).

$V R N 2$ is a long day (LD) flowering repressor with no clear ortholog in Arabidopsis (Yan et al. 2004a). The closest VRN2 ortholog in rice, Ghd7 (colinear with wheat CONSTANS-like 9), is also a long day flowering repressor (Xue et al. 2008), but is not regulated by vernalization. The wheat VRN2 locus includes two related paralogs designated ZCCT1 and ZCCT2 (Yan et al. 2004a), based on the presence of two putative zinc fingers and CCT domains (for $\underline{C O}, \underline{C O}$-like, $\underline{T O C 1) . ~ S i m u l t a n e o u s ~ d e l e t i o n s ~ o r ~ m u t a t i o n s ~}$ of both ZCCT1 and ZCCT2 genes (in all homoeologs) are associated with recessive alleles for spring growth habit (Yan et al. 2004a; Distelfeld et al. 2009b; Hemming et al. 2009). The main role of VRN2 is to repress the induction of VRN3 in the fall, to prevent the induction of flowering before the winter.

VRN3 is a close homolog to the FLOWERING LOCUS $T$ in Arabidopsis, and is also referred to as TaFT1 (Yan et al. 2006). In Arabidopsis, the FT protein is induced in the leaves by long days and is then transported to the apices where it interacts with FLOWERING LOCUS D (FD) and binds to the $A P 1$ promoter to induce flowering (Wigge et al. 2005). A similar result has been described in wheat, where the VRN3 protein interacts with FLOWERING LOCUS D-like 2 (FDL2), which has been shown to bind to the VRN1 promoter in vitro ( $\mathrm{Li}$ and Dubcovsky 2008). $V R N 3$ integrates signals from the photoperiod (CO1, CO2 and $P P D$ ) and vernalization (VRN1 and VRN2) pathways (Yan et al. 2006; Dubcovsky et al. 2006; Hemming et al. 2008, 2009). VRN3 alleles with unusually high levels of expression are associated with dominant spring growth habit in both wheat (Yan et al. 2006) and barley (Nitcher et al. 2013). Before vernalization, VRN3 transcript levels are maintained at low levels by VRN2. During vernalization, the upregulation of VRNI in the leaves results in the downregulation of $V R N 2$ and the release of $V R N 3$, which can further upregulate VRNI in the leaves (then transported to the apices), generating a positive feedback regulatory loop that results in the irreversible induction of flowering (Loukoianov et al. 2005; Chen and Dubcovsky 2012).

$V R N-D 4$ has not been cloned so far and is not as wellcharacterized as the three vernalization genes described above. The dominant spring allele Vrn-D4 is found mainly in hexaploid wheat varieties from Asia, especially in India and nearby regions (Iwaki et al. 2000, 2001). The Vrn-D4 allele was transferred to Western wheat varieties from the Indian cultivar Muzaffarnagar into the cultivar Gabo, which was widely cultivated in Australia between the late 1940s and the late 1960s (O'Brien et al. 2001). Gabo was then 
backcrossed into Triple Dirk to develop an isogenic line named "TDF", that is the designated genetic stock for the dominant Vrn-D4 allele (Pugsley 1972). Incorrect stocks of TDF generated conflicting results on the effect of $V r n-D 4$, but it was recently confirmed that the stock maintained at Okayama University, Japan (designated TDF-J) has the correct Vrn-D4 (Yoshida et al. 2010). A low-resolution genetic linkage map placed the $V R N-D 4$ gene on the centromeric region of chromosome $5 \mathrm{D}$, within a $1.8 \mathrm{cM}$ interval flanked by SSR markers $c f d 78$ on the short arm and barc205 on the long arm, and far from $V R N-D 1$ which is located in the middle of the long arm (Yoshida et al. 2010).

The centromeric region of homoeologous group 5 includes the TaVILI gene (Fu et al. 2007) which encodes a homolog of the Arabidopsis homodomain (PHD) finger protein VIL1 (VERNALIZATION INSENSITIVE 3(VIN3)-LIKE 1). This protein, together with VIN3, plays an important role in the epigenetic memory of vernalization and has an additional role in the photoperiodic regulation of flowering time in Arabidopsis (Sung et al. 2006). Based on its similarity with the Arabidopsis VILl, its centromeric location and its transcriptional upregulation during vernalization, the wheat TaVIL-DI gene was previously considered as a potential candidate gene for $V R N-D 4$ (Fu et al. 2007).

In this study, we sequenced the wheat TaVIL-DI gene in lines carrying different $V R N-D 4$ alleles to evaluate its potential as a candidate gene for $V R N-D 4$, and developed a high-density genetic map of the $5 \mathrm{D}$ centromeric region to precisely map both genes. We mapped $V R N-D 4$ into a $0.09 \mathrm{cM}$ interval in the centromeric region of chromosome 5D, and identified the colinear regions in Brachypodium distachyon and rice. Since $V R N-D 4$ was completely linked to the centromere of chromosome 5D, we generated telocentric stocks 5DS and 5DL from TDF-J to further dissect this region. Finally, we characterized the epistatic interactions between $V R N-D 4$ and the other vernalization genes to better understand the role of $V R N-D 4$ in the wheat vernalization pathway.

\section{Materials and methods}

Plant materials

Near isogenic line Triple Dirk F was obtained from Okayama University, Japan (TDF-J, hereafter), and is the same line as the one used for the initial low-density mapping of $V R N-D 4$ on chromosome 5D (Yoshida et al. 2010). TDF-J has a spring growth habit determined by the dominant $\mathrm{Vrn}$ D4 allele and carries alleles for winter growth habit for all the homoeologs of the other three vernalization genes (vrn1, Vrn2, and vrn3).
TDF-J was crossed with a disomic substitution line of Aegilops tauschii chromosome 5D in Chinese Spring designated hereafter $\mathrm{CS}\left(5 \mathrm{D}_{5402}\right)$. A segregating population of $1,591 \mathrm{~F}_{2}$ plants $(3,182$ gametes) was generated from this cross to construct the $V R N-D 4$ high-density map. $\operatorname{CS}\left(5 \mathrm{D}_{5402}\right)$ was selected as a parental line because of its extensive polymorphism with $T$. aestivum chromosome 5D (http://wheat.pw.usda.gov/SNP/new/index.shtml). Wheat chromosome 5D has low genetic diversity (Akhunov et al. 2010) which makes its mapping exceedingly difficult. To develop CS $\left(5 \mathrm{D}_{5402}\right)$, synthetic wheat RL5402 was crossed as a male with CS monotelosomic 5DL, monosomic progeny was selected, and four times backcrossed to the monotelosomic, selecting a monosomic progeny in each backcross generation. Synthetic wheat RL5402 is a hexaploid amphiploid produced from a cross of tetraploid wheat 'Tetra Canthatch' with Ae. tauschii ssp. tauschii RL5261 (Kerber 1964; Kerber and Rowland 1974). CS(5D D $\left._{502}\right)$ has a winter growth habit, because the replacement of CS chromosome 5D by Ae. tauschii chromosome 5D resulted in the replacement of the $V r n-D l$ allele for spring growth habit by the $v r n-D 1$ allele for winter growth habit.

Chinese Spring nulli-tetrasomic lines for chromosome 5D and ditelosomic line Dt5DL carrying only the long arm of chromosome 5D (Endo and Gill 1996; Linkiewicz et al. 2004; Sears and Sears 1979) were employed to determine the chromosome and arm location of the markers used in this study. Arm locations were validated using DNAs extracted from flow-sorted 5DS and 5DL telocentric chromosomes from CS (Institute of Experimental Botany, Olomouc, Czech Republic).

To determine the arm location of $V R N-D 4$ telocentric chromosomes for 5D TDF-J were produced by centric misdivision of a 5D univalent generated from the cross between nulli-tetrasomic stock CSN5DT5B and TDF-J. The $\mathrm{F}_{1}$ plants were self-pollinated and $192 \mathrm{~F}_{2}$ plants were screened by $\mathrm{C}$-banding for the presence of misdivision products using the methods described before (Lukaszewski and Gustafson 1983).

\section{Growth conditions}

Plants were grown in a greenhouse under non-vernalizing temperatures $\left(20-25^{\circ} \mathrm{C}\right)$ and long day photoperiod $(16 \mathrm{~h}$ light). Natural day length in the greenhouses was supplemented with incandescent lamps at night to extend the photoperiod to $16 \mathrm{~h}$. Heading times were registered from sowing to spike emergence.

Genetic and physical maps

Primers for the seven microsatellite markers included in the high-density map (barc143, gdm3, wmc318, barc205, 
$c f d 67, c f d 78$ and $c f d 81)$ were obtained from the GrainGenes database (http://wheat.pw.usda.gov/GG2/). Primers, PCR conditions, restriction enzymes and size of the indel polymorphism for the 19 sequence-based markers developed in this study are listed in Table S1 (supplemental materials). These markers included cleavage amplified polymorphic sequences (CAPs) and sequence tag site (STS). Information for marker $B G 313707$ has been previously published (Yoshida et al. 2010). Markers were assigned to chromosomes and chromosome arms using the genetic stocks described above.

Genomic DNA was extracted from young leaves of individual plants using the cetyltrimethylammonium bromide (CTAB) method (Murray and Thompson 1980). PCR reactions were conducted in a total volume of $20 \mu \mathrm{l}$ containing $10 \mathrm{mM}$ Tris- $\mathrm{HCl}, \mathrm{PH} 8.3,50 \mathrm{mM} \mathrm{KCl}, 2 \mathrm{mM}$ $\mathrm{MgCl}_{2}, 0.2 \mathrm{mM}$ dNTP, $0.5 \mu \mathrm{M}$ of each primer, 50-100 ng of genomic DNA, and $0.5 \mathrm{U}$ Taq DNA polymerase. PCR amplification was performed at $94{ }^{\circ} \mathrm{C}$ for $5 \mathrm{~min}$, followed by 40 cycles of $94{ }^{\circ} \mathrm{C}$ for $30 \mathrm{~s}$, annealing for $30 \mathrm{~s}$, and $72{ }^{\circ} \mathrm{C}$ for $1 \mathrm{~min} / \mathrm{kb}$, with a final extension at $72{ }^{\circ} \mathrm{C}$ for $7 \mathrm{~min}$.

Annealing temperatures for different microsatellite markers were as follows: $57{ }^{\circ} \mathrm{C}$ for $g d m 68, c f d 78$ and barc143; $60{ }^{\circ} \mathrm{C}$ for $c f d 67, g d m 3$ and $w m c 318 ; 65{ }^{\circ} \mathrm{C}$ for bac205, and $60{ }^{\circ} \mathrm{C}$ for marker TaVIL1. PCR products for markers BE445181, BE499257, BE591275, BE606654, DQ512349 $(=$ TaAGL31), BE403761, BJ315664, CJ521028, and $B E 444702$ were separated on $1 \%$ agarose gels. All other sequence-based markers and SSR markers were separated on $6 \%$ polyacrylamide gels. All gels were stained and visualized with $2 \%$ ethidium bromide.

\section{Characterization of TaVIL-DI and other candidate genes}

The initial TaVIL1 sequences were obtained from TmVIL$A^{m} 1$ from Triticum monococcum (Fu et al., 2007) and from BAC clone WCS1202I10 (AB845602), selected from the Chinese Spring BAC library (Allouis et al. 2003) using a PCR marker for TaVIL-DI. Primers and PCR conditions used to re-sequence TaVIL-DI in the different genetic backgrounds are listed in Table S2. We first sequenced the VIL1 gene from diploid wheat and Aegilops species Ae. tauschii (D genome, AB845601), Ae. speltoides (S genome closely related to the B genome of wheat, AB845599 and AB845600) and Triticum urartu (A genome, AB845597 and $\mathrm{AB} 845598$ ) to obtain sequences related to the A, B and $\mathrm{D}$ genomes of hexaploid wheat, respectively. Based on these sequences, we designed D-genome-specific primers and tested them in nulli-tetrasomic lines for homoeologous group 5 . The D-genome specific primers were then used to sequence TaVIL-DI in hexaploid wheat lines TDFJ, CS(5D 5402$)$, Triple Dirk C (TDC), and two Japanese winter wheats lines (Hayakomugi and Akakawaaka). A similar strategy was used to retrieve the D-genome-specific sequences of other $V R N-D 4$ candidate genes.

The TaVIL- $D 1$ sequenced region including $1 \mathrm{~kb}$ upstream from the start codon and $1.2 \mathrm{~kb}$ downstream from the stop codon, was compared among TDF-J, TDC, Hayakomugi, Akakawaaka, and $\mathrm{CS}\left(5 \mathrm{D}_{5402}\right)$, and polymorphisms were tested for association with differences in growth habit and $V R N-D 4$ alleles. A 12 bp indel polymorphism in TaVIL-DI exon 2 identified between TDF-J and CS $\left(5 \mathrm{D}_{5402}\right)$ was used to integrate TaVIL-Dl into the high-density map (primers VIL1-D-F2 GTTGTTTCCTGTCCATACTAACGC, and VIL1-D-R2 GGCTTTTTGTCTTGAAACATTTT).

Comparative genomics analysis and gene analysis

To delimit the region on $B$. distachyon that is colinear with the $V R N-D 4$ candidate region in wheat, sequences of the wheat Expressed Sequence Tags (ESTs) flanking VRN-D4 were used as queries to search the $B$. distachyon genome (Brachy1.0 database, http://www.brachypodium.org/) using the BLASTN algorithm. The B. distachyon genes were then used to find the rice orthologs at the National Center for Biotechnology Information (NCBI, http://www.ncbi.nlm. nih.gov/blast/Blast.cgi) and Department of Energy's Joint Genome Institute and the Center for Integrative Genomics website (http://www.phytozome.net). Since rice does not have a vernalization response and is evolutionarily less related to wheat compared to $B$. distachyon, we focused on the $B$. distachyon colinear region to search for potential $V R N-D 4$ candidate genes.

Conserved domains present in the $B$. distachyon proteins encoded by the genes present in the colinear candidate region were analyzed using the Conserved Domain Search at NCBI (http://www.ncbi.nlm.nih.gov/Structure/cdd/cdd.s $\mathrm{html}$ ) and InterPro Scan at EMBL-EBI (http://www.ebi.ac. uk/Tools/pfa/iprscan/).

Based on this information and on the annotation of these genes in other species, we identified transcription factors and genes known to be involved in development. We searched for the closest wheat homologs in wheat NCBI databases, genomic sequences from flow-sorted wheat chromosomes arms developed by the International Wheat Genome Sequencing consortium (IWGSC, http://urgi. versailles.inra.fr), and recent wheat transcriptomes (Krasileva et al. (2013), http://maswheat.ucdavis.edu/Transcriptome/). We then did a reverse BLASTP of the best wheat candidate to the $B$. distachyon proteome to confirm that the correct homolog was found.

Expression analysis of candidate genes by qRT-PCR

RNA samples were extracted from leaves using the Spectrum Plant Total RNA Kit (Sigma-Aldrich). Purified RNA 
samples were checked for RNA integrity by running $0.5 \mu \mathrm{g}$ RNA on a $1 \%$ agarose gel. All samples showed clear $18 \mathrm{~S}$ and 26S ribosomal RNA bands indicating lack of RNA degradation. Forward primers for the qRT-PCR (CCAGATGCTGCAAAGCACTA and GAGCTCATTCTTCCTGGCC, efficiency $91 \%$ ) were designed in conserved regions of the A-, B- and D-genome copies of TaAGL31, the reverse primer was designed to anneal over a conserved exon-junction site to avoid amplification on genomic DNA. Melting curves showed a single peak, which confirmed amplification of a single product. Standard curves were constructed to calculate amplification efficiency for the SYBR Green ${ }^{\circledR}$ system developed for TaAGL31. Quantitative PCR was performed using SYBR Green ${ }^{\circledR}$ and a 7500 Fast Real-Time PCR system (Applied Biosystems). ACTIN was used as an endogenous control using primers described before (Uauy et al. 2006). Transcript levels are expressed as linearized fold-ACTIN levels calculated by the formula $2^{\left(\text {ACTIN } \mathrm{C}_{\mathrm{T}}-\text { TARGET } \mathrm{C}_{\mathrm{T}}\right)}$.

\section{Epistatic interactions}

To evaluate the epistatic interactions among VRN1 and the other known vernalization genes, we developed four different segregating populations. The TDF-J line was crossed with Triple Dirk near isogenic lines (NILs) TDD, TDB and TDE carrying the Vrn-Al, Vrn-Bl and Vrn-Dl dominants alleles, respectively [described by Yoshida et al. (2010)]. An additional $F_{2}$ population was developed from the cross between TDF-J and CS(Hope7B) chromosome substitution line (Yan et al. 2006) to test the epistatic interactions between Vrn-D4 and Vrn-B3 $(=F T$ $B 1$ ). The Hope 7B chromosome introgressed into CS carries a highly expressed $V r n-B 3$ allele with a repetitive element inserted in the promoter region of $F T$ (Yan et al. 2006). Approximately, 100 plants per $F_{2}$ population were planted in a greenhouse (all four populations in the same experiment) under non-vernalizing $\left(\geq 24^{\circ} \mathrm{C}\right)$ and long day (16 h light) conditions. The $V r n-A 1, B 1, D 1$ and $V r n-B 3$ genotypes of the $\mathrm{F}_{2}$ plants were determined by PCR using primers described before (Fu et al. 2005; Yan et al. 2006). The VRN-D4 genotype was inferred using SSR marker barc205 located $1.2 \mathrm{cM}$ distal from VRN-D4 (Yoshida et al. 2010).

The number of days between planting and complete emergence of the first spike was scored for each $\mathrm{F}_{2}$ plant. The data was evaluated in three $2 \times 3$ factorial ANOVA considering $V R N-D 4$ and each of the other vernalization loci as factors with three levels: homozygous $V r n-D 4$, heterozygous, and homozygous vrn-D4. In the case Vrn-B3 $\times$ Vrn$D 4$, an additional gene $(V r n-D l)$ segregates in the $\mathrm{F}_{2}$ population, so only a subpopulation of 33 plants carrying the winter allele for $V r n-D 1$ was tested for epistatic interactions between $V r n-B 3$ and Vrn-D4 genes. Statistical analyses were performed using SAS version 9.3. Adjusted LS means are reported with their respective standard errors (SE).

The degree of dominance was calculated using the formula: $D=\left(2 X_{2}-X_{1}-X_{3}\right) /\left(X_{1}-X_{3}\right)$ (Falconer 1960) where $X_{1}, X_{2}$ and $X_{3}$ are the heading time (HT) values of, respectively, the plants homozygous for the late flowering allele (vrn), the heterozygous, and the plants homozygous for the early flowering allele $(V r n)$.

We also compared the effect of $V r n-D 4$ relative to other vernalization genes $(V r n X)$ on heading time (HT) when each gene was present in heterozygous state in a winter genetic background using the formula: Relative single dose effect $=$ $\mathrm{HT}(V r n D 4 / v r n D 4 v r n X / v r n X)-\mathrm{HT}(\operatorname{VrnX} / v r n X v r n D 4 / v r n D 4)$.

\section{Results}

Sequencing of TaVIL-Dl candidate gene

The TaVIL-DI gene region was sequenced in TDF-J (AB846583) and five lines not carrying the Vrn-D4 allele for early flowering: Hayakomugi (AB846584), CS(5D 5402$)$ (AB846585), TDC (AB846586), Akakawaka (AB846587) and Ae. tauschii (AB845601). The sequenced regions extended from $1 \mathrm{~kb}$ upstream of the start codon to $1.2 \mathrm{~kb}$ downstream of the stop codon, providing a total coverage of $5.4 \mathrm{~kb}$. All these lines, with exception of TDF-J, have a winter growth habit.

The only polymorphisms found in these sequences were between the lines carrying the 5D chromosome from T. aestivum and the ones carrying the 5D chromosome from Ae. tauschii $\left[\mathrm{CS}\left(5 \mathrm{D}_{5402}\right)\right.$ and Ae. tauschii differ in a single SNP in the fourth exon]. $\mathrm{CS}\left(5 \mathrm{D}_{5402}\right)$ has $18 \mathrm{SNPs}$, four deletions and one insertion compared with the 5D sequences from the T. aestivum lines. Among the six SNPs present in the exons, five were associated with non-synonymous substitutions. In addition, we found a 12 bp deletion in exon 2 that resulted in the deletion of four amino acids in $\mathrm{CS}\left(5 \mathrm{D}_{5402}\right)$, but all were located outside of the PHD finger, FNIII, or VID conserved domains.

We found no polymorphisms in the TaVIL-Dl coding regions or in the $5^{\prime}(1.0 \mathrm{~kb})$ and $3^{\prime}(1.2 \mathrm{~kb})$ regions between the spring TDF-J (Vrn-D4 allele) and the three T. aestivum lines with winter growth habit (Hayakomugi, TDC, and Akakawaaka, vrn-D4 allele). The sequencing data suggests that TaVIL-DI is an unlikely candidate for $V R N-D 4$, but we could not rule out the possibility of a polymorphic regulatory sequence outside the sequenced region. To provide more conclusive evidence, we developed a high-density mapping population from the cross TDF-J $\times \mathrm{CS}\left(5 \mathrm{D}_{5402}\right)$ and screened it for recombination events within the $V R N$ D4 region, which includes the TaVIL-D1 gene. 
A

Wheat 5D

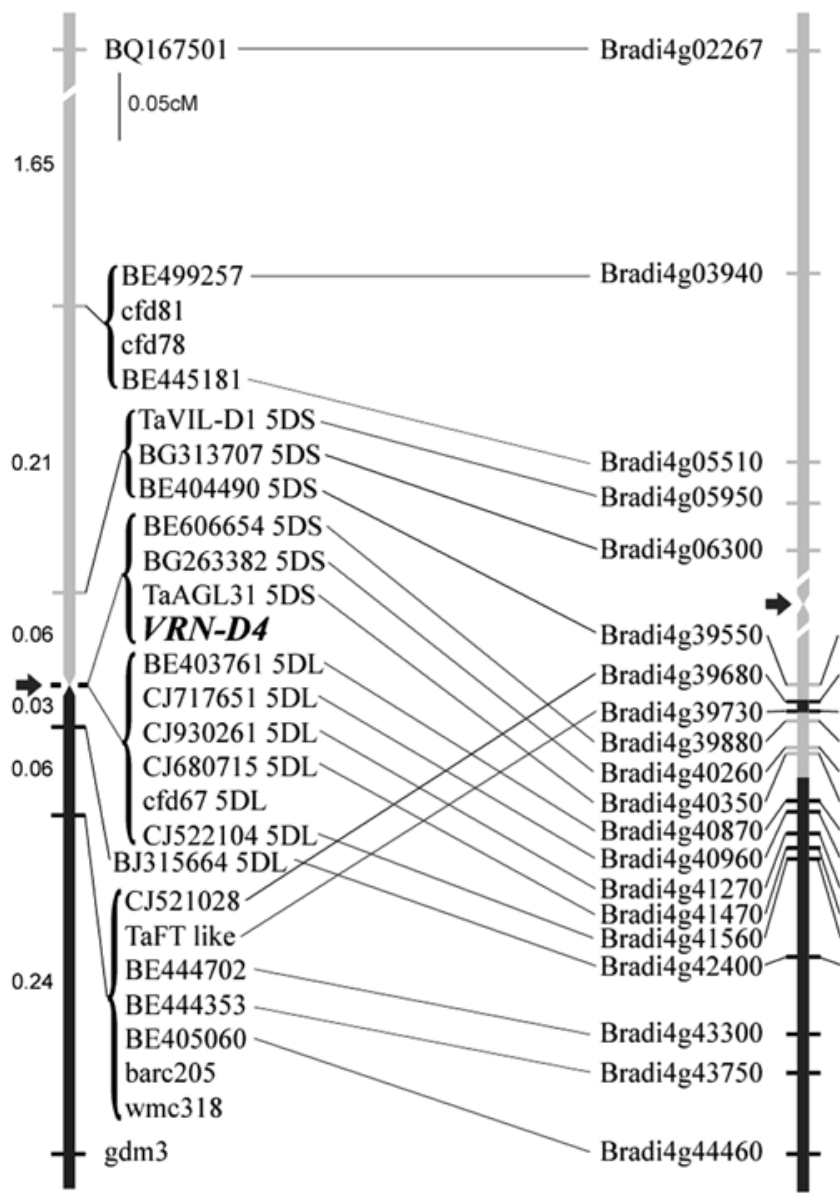

B

Brachypodium 4
C

Rice 12

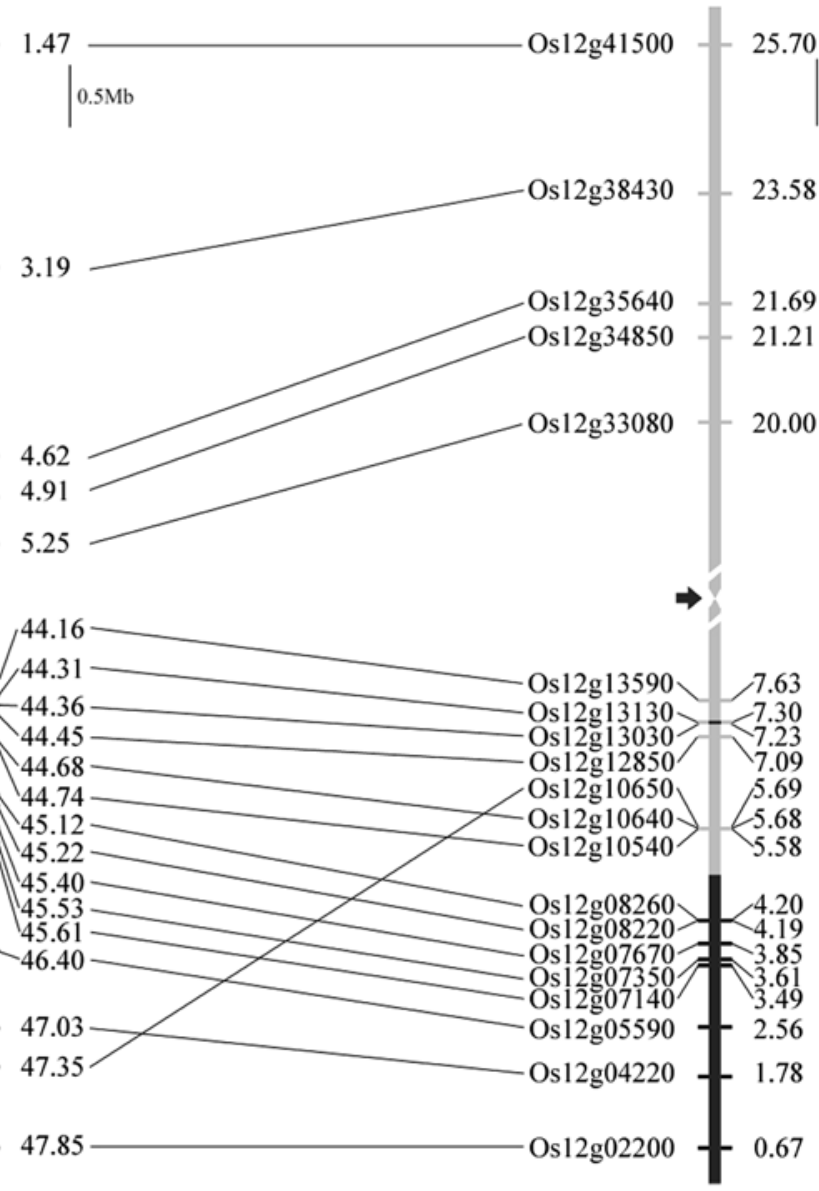

collinar to wheat short arm

collinar to wheat long arm
Fig. 1 High-density comparative map of the $V R N-D 4$ candidate region. a High-density genetic map of the $V R N-D 4$ in hexaploid wheat cross TDF-J $\times \mathrm{CS}\left(5 \mathrm{D}_{5402}\right)$. Distances are in $\mathbf{c M}$. b, $\mathbf{c}$ Maps of $B$. distachyon and rice colinear regions with $V R N-D 4$ region. Dis-

\section{High-density map of $V R N-D 4$}

We mapped the TaVIL-DI gene close to the centromeric region of wheat chromosome arm 5DS. We also detected homoeologs of TaVIL-D1 in the sequences of the 5AS and 5BS sorted chromosome arms sequenced by the IWGSC (http://wheat-urgi.versailles.inra.fr/SeqRepository/BLAST), and in the sequences of barley chromosome arm 5HS, suggesting a conserved position in the Triticeae. Orthologs of TaVIL-D1 were found in the colinear regions of $B$. distachyon chromosome 4 (Brad4g05950, $4.91 \mathrm{Mb})$ and rice chromosome 12 (Os12g34850, 21.21 Mb) (Fig. 1).

In spite of the limited recombination observed in the centromeric region of chromosome 5D in this segregating tances are in $\mathrm{Mb}$ and are based on current genome sequences. Arrows indicate active centromeres, centromeric regions are not drawn to scale. b B. distachyon chromosome 4. c Rice chromosome 12

population (Yoshida et al. 2010), the expansion of the mapping population to $1,591 \mathrm{~F}_{2}$ plants $(3,182$ gametes) yielded two independent recombination events between TaVIL-DI and $V R N-D 4$ (Table 1, plant 189 and 768). Heading times for the progeny tests of these two critical plants (bottom row of Table 1) demonstrated that they were heterozygous for Vrn-D4 but homozygous for TaVIL-D1. These recombination events, together with the lack of TaVIL-D1 polymorphisms between TDF-J (Vrn-D4 allele) and both TDC and the two hexaploid Japanese wheat cultivars ( $v r n-D 4$ allele), indicate that the wheat TaVIL-D1 gene is a very unlikely candidate gene for $V R N-D 4$.

To further dissect the VRN-D4 region, we developed nineteen new sequence-based molecular markers in the centromeric region of chromosome 5D using wheat ESTs 
Table 1 Graphical representation of haplotypes in the critical recombinants

\begin{tabular}{|c|c|c|c|c|c|c|}
\hline \multirow[t]{2}{*}{ Markers } & \multicolumn{6}{|c|}{ Critical Recombinants } \\
\hline & no. 189 & no. 366 & no. 768 & no. 1423 & no. 1279 & no. 1572 \\
\hline$B Q 167501$ & A & $\mathrm{H}$ & B & B & A & A \\
\hline$c f d 81$ & A & $\mathrm{H}$ & - & B & - & $\mathrm{H}$ \\
\hline$c f d 78$ & A & - & B & - & A & - \\
\hline BE499257 & A & $\mathrm{H}$ & B & B & A & $\mathrm{H}$ \\
\hline BE445181 & A & $\mathrm{H}$ & B & B & & $\mathrm{H}$ \\
\hline TaVIL-D1 & A & $\mathrm{H}$ & B & $\mathrm{H}$ & A & $\mathrm{H}$ \\
\hline BG313707 & $\mathrm{D}$ & $\mathrm{D}$ & B & - & & - \\
\hline BE404490 & A & $\mathrm{H}$ & B & $\mathrm{H}$ & A & $\mathrm{H}$ \\
\hline BE606654 & $\mathrm{H}$ & $\mathrm{H}$ & $\mathrm{H}$ & $\mathrm{H}$ & A & $\mathrm{H}$ \\
\hline$B G 263382$ & $\mathrm{H}$ & $\mathrm{H}$ & $\mathrm{H}$ & $\mathrm{H}$ & A & $\mathrm{H}$ \\
\hline TaAGL31 & $\mathrm{H}$ & $\mathrm{H}$ & $\mathrm{H}$ & $\mathrm{H}$ & A & $\mathrm{H}$ \\
\hline$V R N-D 4$ (heading) & $\mathbf{H}$ & $\mathbf{H}$ & $\mathbf{H}$ & $\mathbf{H}$ & $\mathbf{A}$ & $\mathbf{H}$ \\
\hline \multicolumn{7}{|l|}{$\underline{\text { Centromere }}$} \\
\hline BE403761 & $\mathrm{H}$ & $\mathrm{H}$ & $\mathrm{H}$ & $\mathrm{H}$ & A & $\mathrm{H}$ \\
\hline CJ717651 & $\mathrm{H}$ & $\mathrm{H}$ & $\mathrm{H}$ & $\mathrm{H}$ & A & $\mathrm{H}$ \\
\hline CJ930261 & $\mathrm{H}$ & $\mathrm{H}$ & $\mathrm{H}$ & $\mathrm{H}$ & A & $\mathrm{H}$ \\
\hline CJ680715 & - & $\mathrm{H}$ & $\mathrm{H}$ & $\mathrm{H}$ & A & $\mathrm{H}$ \\
\hline$c f d 67$ & $\mathrm{H}$ & $\mathrm{H}$ & $\mathrm{H}$ & $\mathrm{H}$ & A & $\mathrm{H}$ \\
\hline CJ522104 & $\mathrm{H}$ & $\mathrm{H}$ & $\mathrm{H}$ & $\mathrm{H}$ & A & $\mathrm{H}$ \\
\hline BJ315664 & $\mathrm{H}$ & $\mathrm{H}$ & $\mathrm{H}$ & $\mathrm{H}$ & $\mathrm{H}$ & $\mathrm{H}$ \\
\hline CJ521028 & $\mathrm{H}$ & B & $\mathrm{H}$ & $\mathrm{H}$ & $\mathrm{H}$ & B \\
\hline TaFTL-1 & $\mathrm{H}$ & B & $\mathrm{H}$ & $\mathrm{H}$ & $\mathrm{H}$ & B \\
\hline BE444702 & $\mathrm{H}$ & B & $\mathrm{H}$ & $\mathrm{H}$ & $\mathrm{H}$ & B \\
\hline BE444353 & $\mathrm{H}$ & B & $\mathrm{H}$ & $\mathrm{H}$ & $\mathrm{H}$ & B \\
\hline BE405060 & $\mathrm{H}$ & B & $\mathrm{H}$ & $\mathrm{H}$ & $\mathrm{H}$ & B \\
\hline barc 205 & $\mathrm{H}$ & B & $\mathrm{D}$ & $\mathrm{D}$ & $\mathrm{D}$ & B \\
\hline wmc318 & $\mathrm{H}$ & B & $\mathrm{H}$ & $\mathrm{H}$ & $\mathrm{H}$ & B \\
\hline$g d m 3$ & $\mathrm{H}$ & B & $\mathrm{C}$ & $\mathrm{C}$ & $\mathrm{C}$ & $\mathrm{C}$ \\
\hline barc143 & $\mathrm{H}$ & B & $\mathrm{H}$ & $\mathrm{H}$ & $\mathrm{H}$ & B \\
\hline PT genotyped & $c f d 67$ & $c f d 67$ & cfd67 & barc 205 & BJ315664 & BE606654 \\
\hline$A$ & $85.7 \pm 2.51$ & $83.4 \pm 3.31$ & $66.3 \pm 2.60$ & $73.8 \pm 2.04$ & $51.6 \pm 0.61$ & $63.4 \pm 3.37$ \\
\hline$B$ & $139.0 \pm 2.00$ & $134.7 \pm 2.53$ & $132.0 \pm 2.30$ & $103.4 \pm 1.48$ & $58.1 \pm 2.84$ & $118.5 \pm 3.90$ \\
\hline$H$ & $116.2 \pm 5.46$ & $107.4 \pm 4.50$ & $106.5 \pm 2.33$ & $97.3 \pm 1.94$ & $57.1 \pm 1.76$ & $102.0 \pm 4.65$ \\
\hline$P A N O V A$ & S & S & $S$ & S & NS & $S$ \\
\hline
\end{tabular}

A change in cell color indicates a recombination event. Heading time of each genotypic class is shown as mean \pm standard error of the mean at the bottom of the Table (the heterozygous marker used to genotype the progeny test (PT) is indicated above)

$A$ TDF-J, $B$ CS(5D $(5402), H$ heterozygous, $C \mathrm{~B}$ or $\mathrm{H}, D$ A or $\mathrm{H}, S$ significant $(P<0.0001)$, $N S$ on-significant
The nine sequence-based markers completely linked to the centromere could not be ordered based on recombination, but were divided into two groups by their arm location. The gene-based markers within these subgroups were ordered on the basis of the orthologous genes in B. distachyon (Fig. 1). To determine the most likely position of SSR marker $c f d 67$ within the 5DL subgroup, we first identified 
A Telocentrics of TDF-J 5D

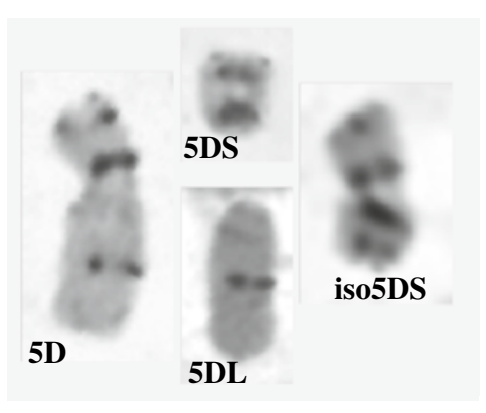

B Effect of TDF-5DS dosage on heading time

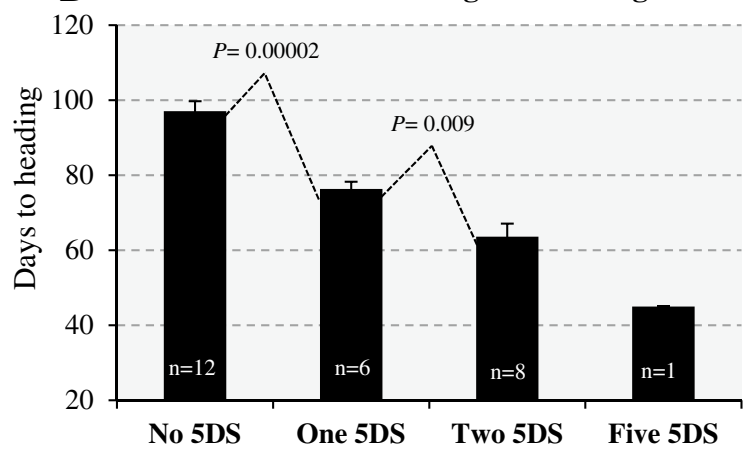

Fig. 2 Use of ditelocentric TDF-J lines to map $V R N-D 4$. a C-Banding of chromosome 5D, telocentric chromosomes 5DS and 5DL and isochromosome iso5D. b Heading time of lines carrying different dosages of the 5DS arms: 0 copies (mt5DL, dt5DL and nullisomics 5D), one copy (mt5DS), two copies (dt5DS and TDF-J), and five copies (dt-iso5DS + 5D). The number of plants in each class is indicated at the base of the bar and the standard error of the mean in the error bars. The $P$ values are the results of two $t$ tests for samples with unequal variances on data transformed to restored normality of residuals (Shapiro-Wilk test not significant). The dt-iso-5DS $+5 \mathrm{D}$ line was not compared statistically because a single plant was obtained in this class. Note the acceleration of flowering with increase dosage of the 5DS chromosome arm
5D scaffold 72311 as the closest match between the $c f d 67$ sequence and the Ae. tauschii genome (Jia et al. 2013). We then identified a gene within this scaffold and identified the $B$. distachyon orthologous gene as Bradi4g41527. Since this $B$. distachyon gene is located between Bradi4g41470 and Bradi4g41560 on chromosome $4(45.59 \mathrm{Mb})$, cfd67 was placed between the orthologous wheat genes CJ680715 and CJ522104.

$V R N-D 4$ co-segregated with three markers mapped on the short arm and six markers mapped on the long arm of chromosome 5D and, therefore, could not be assigned to a specific chromosome arm. To obtain this information, we produced telocentric lines of chromosome 5D from TDF-J.

Mapping of $V R N-D 4$ using monotelosomic and ditelosomic lines of TDF-J

To identify 5DS and 5DL monotelosomic chromosomes, we screened $192 \mathrm{~F}_{2}$ plants for the presence of misdivision products of chromosome 5D from TDF-J by C-banding. We identified two monotelosomic 5DL plants (mt5DL), one monotelosomic 5DS plant (mt5DS) and three plants with a normal 5D chromosome plus one isochromosome 5DS (iso5DS indicates two short arms fused at the centromere) (Fig. 2a).

These plants were grown, self-pollinated and their progenies were screened for the presence or absence of the telocentrics/isochromosomes and for their heading time (Fig. 2b). Since the Vrn-D4 allele from TDF-J is partially dominant for early flowering (Yoshida et al. 2010), the lines missing the arm harboring Vrn-D4 should show delayed heading time. The 12 plants missing the 5DS arm (three $\mathrm{mt5DL}$, four $\mathrm{dt5DL}$ and five nullisomics 5D) flowered $97.1 \pm 2.6$ days after sowing, which is 20.8 days later than the average of the mt5DS plants carrying one copy of the 5DS chromosome (76.3 $\pm 1.9, P=0.00002)$. This result indicates that $V R N-D 4$ is located in the short arm of chromosome 5D. This chromosome location was further confirmed by the comparison between the mt5DS and the combined dt5DS and TDF-J plants, which carry two doses of chromosome arm 5DS and flowered 12.7 days earlier $(63.6 \pm 3.5, P=0.009)$ than the plants carrying one dose. No statistical comparison was made with the diiso5DS $+5 \mathrm{D}$ ( 5 doses of 5DS), because only a single plant was recovered with this genotype. However, it is still interesting to point out that this was, by far, the earliest flowering line (45 days). Taken, together the data from this experiment consistently indicate that $V R N-D 4$ is located in the short arm of chromosome 5D.

$V R N-D 4$ candidate genes in B. distachyon colinear region

The DNA sequences of the markers mapped on the centromeric region of chromosome 5D were used to delimit the colinear regions in $B$. distachyon genome (http://www.brachypodium.org) and in rice (http://www.phytozome.net). The 7 bins including the 20 wheat sequence-based markers (Fig. 1) showed good colinearity with B. distachyon, except for loci CJ521028 and TaFT-like (we do not know the order of the wheat markers completely linked within a bin). All these $B$. distachyon genes, except one (Bradi4g43750), were colinear between $B$. distachyon and rice. In spite of the good colinearity observed in this region, the centromere of wheat chromosome 5D was mapped in a non-colinear position. Using the Chinese Spring ditelocentric 5DL chromosome, the wheat 
5D centromere was mapped between markers TaAGL31 and $B E 403761,0.06 \mathrm{cM}$ proximal to the position of the centromere predicted by rice and $B$. distachyon (Fig. 1). The closest markers flanking the wheat 5D centromere are colinear with a region in B. distachyon chromosome 4 (44.74-45.12 Mb) that is $22 \mathrm{Mb}$ apart from the active $B$. distachyon centromere (22.5-22.9 Mb, Qi et al. 2010). The same wheat markers are colinear with a region in rice chromosome $12(4.21-5.58 \mathrm{Mb})$ that is $6.4 \mathrm{Mb}$ apart from the location of the rice centromere (12 Mb, Qi et al. 2010).

We then looked for putative candidate genes for $V R N$ $D 4$ in the colinear region of the sequenced $B$. distachyon genome (closer to wheat than rice). Wheat genes flanking $V R N-D 4, \mathrm{BE} 404490$ on the short arm and BE403761, the most proximal marker in the long arm (Fig. 1 and Linkiewicz et al.2004), were used to delimit the colinear region on $B$. distachyon chromosome 4 between orthologous genes Bradi4g39550 and Bradi4g40870. The selected B. distachyon region is roughly $1 \mathrm{Mb}(44.16-45.13 \mathrm{Mb})$ and includes 127 predicted genes (http://www.brachypodium.org). Among these genes, ten have been annotated as transcription factors or developmentally related genes (Table 2) and are discussed in detail below.

Three of the selected $B$. distachyon genes in Table 2 (Bradi4g39630, Bradi4g40057, and Bradi4g40517) showed close homology with wheat genes located in the long arm of chromosome 5D and therefore, were discarded as $V R N-D 4$ candidate genes. This is an expected result, since one of the wheat flanking markers (BE403761) was selected on the long arm to guarantee the inclusion of all the short arm genes. For two of the other B. distachyon genes (Bradi4g40250 and Bradi4g40310), the wheat genes with the lowest $\mathrm{E}$ values were located on wheat chromosome arms 6DS and 7DL, respectively (Table 2). As a result these two genes were also discarded as potential candidates for $V R N-D 4$.

No wheat orthologs were found for another three $B$. distachyon genes in Table 2 (Bradi4g40230, Bradi4g40270, and Bradi4g40357) in any of the searched databases (see "Materials and methods"). Reverse BLAST of the wheat sequences with the lowest $\mathrm{E}$ values back to the $B$. distachyon genome identified a different $B$. distachyon gene from the one used in the original query. These results indicate that the detected wheat genes were paralogs rather than orthologs of these three $B$. distachyon genes. Interestingly, the reverse BLAST of the closest wheat sequences for Bradi4g40230 and Bradi4g40270 (AK333859 and UCW_Tt-k61_contig_71361, 81 and $86 \%$ identity at the DNA level, respectively) detected two close paralogs (Bradi4g21040 and Bradi4g21160) mapping to the same centromeric region of $B$. distachyon chromosome 4. This region is colinear with the centromeric regions of wheat chromosome 4 and rice chromosome 11 , and may represent an ancestral duplication. Rice chromosomes 11 and 12 are known to be the result of an ancient duplication (Paterson et al. 2004; Wu et al. 1998).

Brachypodium distachyon gene Bradi4g40540 showed homology with a sequence on wheat chromosome 5BS (IWGSC_chr5BS_ab_k71_2249326) but no significant similarity was detected with sequences on chromosome arms 5AS or 5DS in the IWGSC database (http://wheaturgi.versailles.inra.fr/Seq-Repository). Annotation of the 5BS genomic sequence revealed the presence of a premature stop codon in the first intron, demonstrating that this sequence corresponds to a pseudogene and therefore, is not a valid candidate for $V R N-D 4$.

The most promising candidate gene for $V R N-D 4$ was the $B$. distachyon gene Bradi4g40350, which showed $90 \%$ identity with the wheat gene TaAGAMOUS-like 31 $($ TaAGL31 = DQ512349), a MADS-box gene related to the floral homeotic gene AGAMOUS in Arabidopsis (Table 2). TaAGL31 is $100 \%$ identical to a sequence detected on chromosome arm 5DS (IWGSC_chr5DS_ab_k71_2764238), the same arm location as VRN-D4. A reverse BLAST confirmed that Bradi4g40350 is the closest B. distachyon gene to this wheat sequence. We sequenced TaAGL31 in the two parental lines of our mapping population [TDF-J and $\left.\mathrm{CS}\left(5 \mathrm{D}_{5402}\right)\right]$ and used one of the detected SNPs to map this gene. TaAGL31 was mapped completely linked to $V R N-D 4$ (Fig. 1; Table 1). We also sequenced the promoter (1,404 bp from the start codon), the first intron, the coding region and the $3^{\prime}$ UTR (438-bp) of this gene in the winter T. aestivum line TDC (vrn-D4) and found no polymorphisms with TDF-J (Vrn-D4) (KF761670 and KF761668 respectively). The TaAGL31 coding region in these two accessions (KF761667, KF761666) was $100 \%$ identical to the Chinese Spring sequence (DQ512349). Finally, we checked the expression of this gene in TDF-J and TDC by qRT-PCR at two different time points (3- and 5-week-old plants, Fig. 4), and found no differences in TaAGL31 transcript levels between these two lines.

Epistatic interaction of $V R N-D 4$ with vernalization genes

The results of the $2 \times 3$ factorial ANOVAs for the four different segregating populations used to test the epistatic interactions between $V R N-D 4$ and other vernalization genes are presented in Table 3. The main effects of $V R N$ $D 4, V R N 1$ three homologs (VRN-A1, VRN-B1 and VRND1), and $V R N-B 3$ were highly significant $(P<0.0001)$ in all four populations. The interactions between $V R N-D 4$ and the other vernalization genes were also highly significant ( $P<0.0001$, Fig. 3a-d). In all four cases, $V R N-D 4$ showed a smaller effect on heading time when the early flowering allele of the other vernalization gene was present than when it was absent (Fig. 3a-d). All plants homozygous for the $v r n-D 4$ and vrn- 1 alleles for winter growth habit segregating in each population showed very late flowering (adjusted 


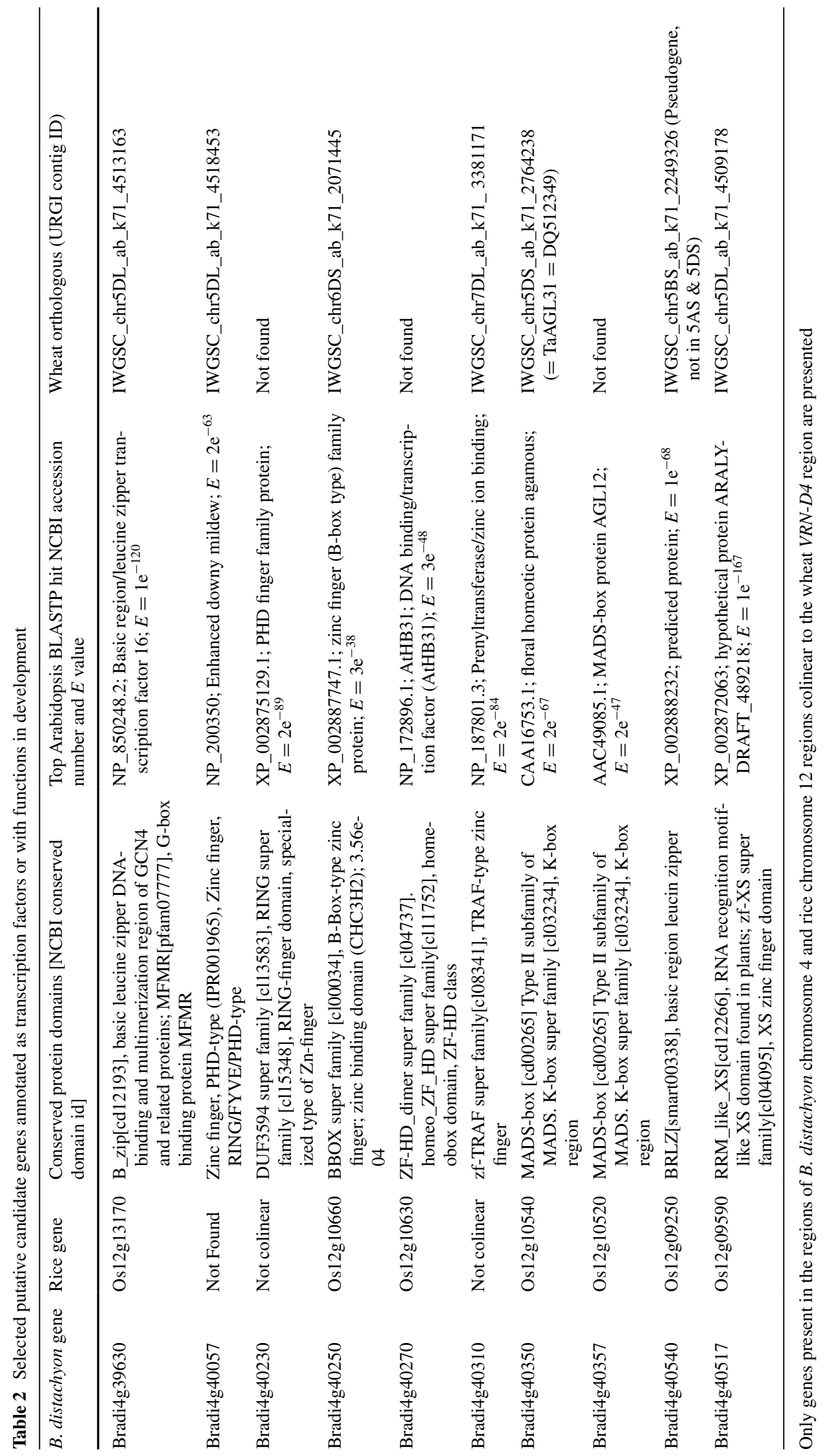


Table 3 Interactions between $V R N-D 4$ and other vernalization genes

\begin{tabular}{lllllllc}
\hline Vrnx & $P$ VrnX & $P$ Vrn-D4 & $P$ interaction & $R^{2}$ & VrnX dominance $^{\mathrm{a}}$ & Vrn-D4 dominance $^{\mathrm{a}}$ & Vrn-D4 - VrnX one dose effect $^{\mathrm{b}}$ \\
\hline Vrn-A1 & $<0.0001$ & $<0.0001$ & $<0.0001$ & 0.96 & $95.9 \%$ & $53.7 \%$ & 18.5 days $^{* * *}$ \\
Vrn-B1 & $<0.0001$ & $<0.0001$ & $<0.0001$ & 0.91 & $55.6 \%$ & $30.7 \%$ & 1.0 days $^{\text {NS }}$ \\
Vrn-D1 & $<0.0001$ & $<0.0001$ & $<0.0001$ & 0.89 & $78.2 \%$ & $42.9 \%$ & 14.3 days $^{* * *}$ \\
Vrn-B3 & $<0.0001$ & $<0.0001$ & $<0.0001$ & 0.87 & $71.0 \%$ & $31.3 \%$ & 18.9 days V $^{* *}$ \\
\hline
\end{tabular}

Probability of main effects and interactions in the $2 \times 3$ factorial ANOVA, proportion of variation explained by the model $\left(R^{2}\right)$ of the model, degree of dominance and relative effect of single dose allele combination

a Degree of dominance was calculated using LS Means and the formula described in "Materials and methods"

b Relative single dose effect was calculated using LS Means and the formula described in "Materials and methods". Positive values indicate that plans carrying the $V r n-D 4$ allele flowered later than plants carrying the $V r n X$ allele

** $P<0.001$, *** $P<0.0001$ and ${ }^{\mathrm{NS}} P>0.05$
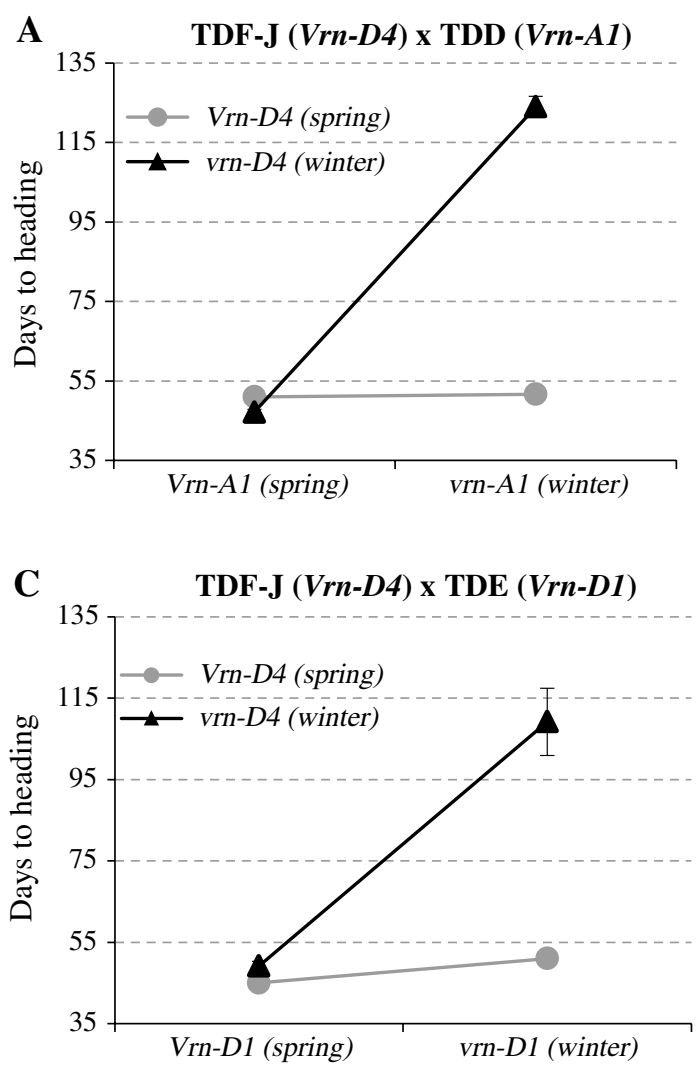

Fig. 3 Interactions between $V R N-D 4$ and other vernalization genes. To facilitate the visualization of the interactions we only included in this figure the plants homozygous for the two vernalization genes segregating in each population. a Interactions between $V R N-D 4$ and $V R N-A 1$. b Interactions between $V R N-D 4$ and $V R N-B 1$. c Interactions

means average between 119 and 130 days, Fig. 3a-d), confirming that there were no additional genes segregating for spring growth habit in these populations. This was also supported by the large proportion of variation in heading time $\left(R^{2}=0.87-0.96\right)$ explained in each population by the
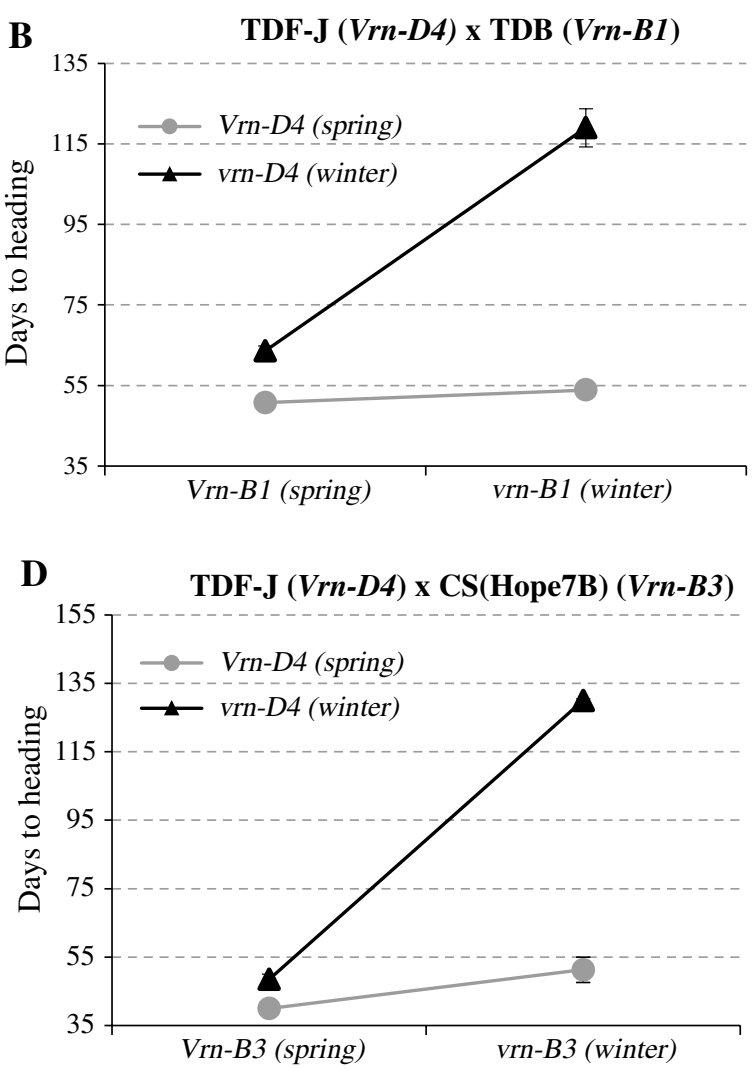

between $V R N-D 4$ and $V R N-D 1$. d Interactions between $V R N-D 4$ and $V R N-B 3$. All the interactions were highly significant $(P<0.0001$, based on $2 \times 3$ factorial ANOVAs including homozygous and heterozygous classes for each gene, Table 3 )

factorial ANOVA models including the two vernalization genes and their respective interactions.

The degree of dominance (D) for the early flowering allele of Vrn-D4 (30.7-53.7\%) was smaller than the degree of dominance of the different Vrnl alleles 


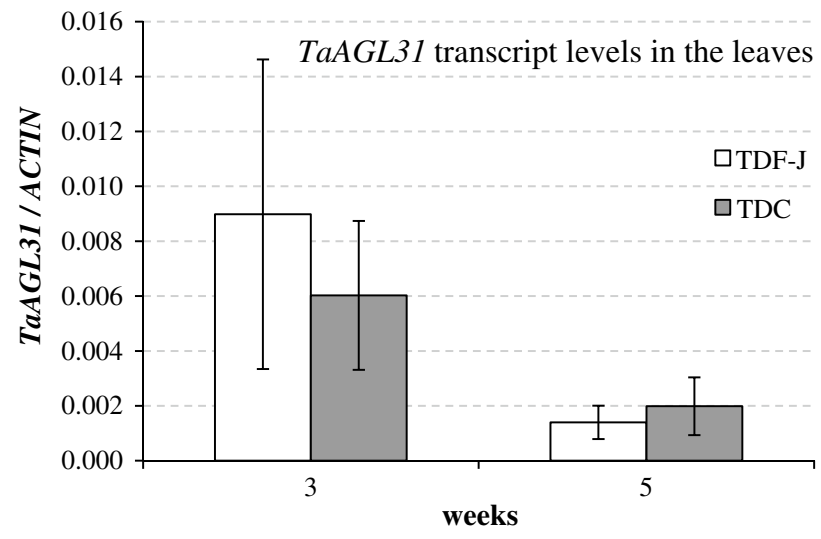

Fig. 4 Comparison of TaAGL31 transcript levels in the leaves of TDF-J (Vrn-D4) and TDC (vrn-D4) at two different time points. Transcript levels are expressed as linearized fold-ACTIN levels calculated by the formula $2^{\left(A C T I N \mathrm{C}_{\mathrm{T}}-T A R G E T \mathrm{C}_{\mathrm{T}}\right)}$. Error bars are $\mathrm{SE}$ of the means calculated from six biological replications

(55.6-95.9\%, Table 3). Among the VRN1 genes, the $V r n-A l$ allele for spring growth habit showed the highest level of dominance, which is consistent with previous studies showing that a single dominant $\mathrm{Vrn}-\mathrm{Al}$ allele is usually sufficient to eliminate the vernalization requirement.

We also showed that the Vrn-D4 allele had a weaker effect to accelerate flowering than the Vrn-Al, Vrn-Dl or $V r n-B 3$ alleles. In genetic backgrounds where all other genes were homozygous for a winter growth habit, plants heterozygous only for Vrn-D4 flowered 14-19 days later than those heterozygous only for Vrn-Al, Vrn-Dl or Vrn$B 3$ (Table 3). No significant differences were detected between $V r n-D 4$ and $V r n-B 1$, which together with the similar dominance values of these two genes suggests that the dominant Vrn-D4 allele has an effect on heading time approximately similar to that of the dominant $V r n-B 1$ allele (Table 3).

\section{Discussion}

\section{$V R N-D 4$ mapping}

In the high-density map presented in this study, we were able to separate $V R N-D 4$ from four of the five markers that were completely linked to $V R N-D 4$ in previous maps (Yoshida et al. 2010), confirming higher resolution of this new map. In addition to the larger number of recombination events, the new map includes 19 new sequence-based markers in the centromeric region of chromosome 5D (short and long arms), which facilitated detailed comparisons with the colinear regions in the sequenced $B$. distachyon and rice genomes.
The high-density map of $V R N-D 4$, and eventually its positional cloning, faces two major challenges. The first one is the limited polymorphisms in the T. aestivum $\mathrm{D}$ genome (Dubcovsky and Dvorak 2007; Akhunov et al. 2010), particularly in the centromeric regions. The second one is the limited recombination in the proximal half of the wheat chromosomes (Luo et al. 2013; Lukaszewski and Curtis 1993). The first problem was addressed in this study by studying recombination between homologous chromosomes 5D from T. aestivum and a divergent Ae. tauschii accession. These two chromosomes showed 120 $\mathrm{SNP}$ in $24.4 \mathrm{~kb}$ sequenced ( $\sim \mathrm{SNP} / \mathrm{kb})$ compared with no SNPs detected in the $37.0 \mathrm{~kb}$ sequenced in chromosome 5D between TDF-J and both TDC and Hayakomugi.

Unfortunately, the higher level of polymorphisms in this population is associated with a $\sim 30 \%$ reduction in recombination frequency (Yoshida et al. 2010). This reduced recombination is possibly associated with the ability of the Pairing homoeologous (Phl) gene (Yousafzai et al. 2010; Griffiths et al. 2006) to detect the relatively high level of heterozygosity between the T. aestivum and Ae. tauschii 5D chromosomes. The $P h l$ gene is known to produce a more drastic reduction in recombination between the A genome of wheat and the $\mathrm{A}^{\mathrm{m}}$ genome from T. monococcum (Dubcovsky et al. 1995), which show an average of $\sim 12 \mathrm{SNP} /$ $\mathrm{kb}$ in intronic regions (Dubcovsky and Dvorak 2007). To solve the problem of the reduced recombination, we are developing new mapping populations in the $p h l b$ mutant background segregating for the same 5D chromosomes from T. aestivum and Ae. tauschii used in this study [TDF-J $\left.\times \mathrm{CS}\left(5 \mathrm{D}_{5402}\right)\right]$. However, even if recombination is restored to levels observed in normal T. aestivum $\times T$. aestivum crosses, the natural low level of recombination near the centromeric regions of wheat chromosomes will continue to complicate efforts to dissect the $V R N-D 4$ region by recombination. We are currently exploring the use of radiation mutants to generate additional break points in the $5 \mathrm{D}$ centromeric region.

Comparative maps of the $V R N-D 4$ candidate region in $B$. distachyon and rice

The previous genetic map of $V R N-D 4$ was mainly based on SSR markers (only one sequence-based marker), limiting the comparisons to sequenced genomes from other grass species (Yoshida et al. 2010). The 20 sequence-based markers on the $5 \mathrm{D}$ centromeric region were mapped to 7 bins that show good colinearity with $B$. distachyon chromosome 4 and rice chromosome 12 (Fig. 1). Most of these $B$. distachyon loci were also colinear with rice, with the exception of Bradi4g43750 (Fig. 1). Two closely linked wheat genes, CJ521028 and FT-like, were not colinear with B. distachyon or rice (Fig. 1). The orthologs of these two 
genes are $0.06 \mathrm{Mb}$ apart on $B$. distachyon chromosome 4 and do not seem to be physically close in wheat since they are located on non-overlapping contigs generated in the different wheat genomic projects (http://wheat-urgi. versailles.inra.fr/Seq-Repository/BLAST; Jia et al. 2013; Ling et al. 2013).

An interesting exception to the relatively good colinearity observed among wheat, $B$. distachyon and rice chromosomes in the VRN-D4 region is the different position of the centromeres. In wheat, we mapped the centromere of chromosome 5D between markers TaAGL31 on the short arm and BE403761 on the long arm. These two markers are completely linked genetically but were separated by the centric breakage in telocentric 5DS and 5DL, and by the use of DNAs from sorted 5DS and 5DL chromosome arms. BE403761 homoeologs have been also mapped in the centromeric region of the long arms on telocentric chromosomes 5BL and 5HL and in two translocations between the short arm of rye 5RS and the long arms of chromosomes 5B and 5D (T5RS.5BL and T5RS.5DL), suggesting conserved break points (Linkiewicz et al. 2004). The markers flanking the centromere on wheat chromosome 5D are colinear with $B$. distachyon markers Bradi4g 40350 and Bradi4g 40870 that delimit a region of chromosome 4 between 44.74 and $45.12 \mathrm{Mb}$. This region is more than $20 \mathrm{Mb}$ distal from the location of the active centromere on $B$. distachyon chromosome 4 [22-23 Mb, Qi et al. (2010)]. Furthermore, pericentromeric probes for wheat chromosome 5 were mapped on the long arm of $B$. distachyon chromosome 4 at positions $44-46 \mathrm{Mb}$ (Qi et al. 2010). This is the same region delimited by Bradi4g40350 and Bradi4g40870, the markers colinear with the wheat 5D centromere. This region appears to be the location of an inactive $B$. distachyon centromere homologous to the active 5D centromere. On the other hand, probes from wheat chromosome 4 hybridized to the $22.5 \mathrm{Mb}$ midpoint of $B$. distachyon chromosome 4 , the expected position of the centromere in this metacentric chromosome (Qi et al. 2010). The sequencing of the $B$. distachyon genome confirmed that the active centromere of $B$. distachyon chromosome 4 is homologous to centromeres of wheat chromosome 4 and rice chromosome 11 (International Brachypodium Initiative 2010).

Rice chromosomes 11 and 12 are the result of an ancient duplication that predates the divergence of the major grass subfamilies (Paterson et al. 2004). The functional centromere of rice chromosome 12 has been mapped at $12 \mathrm{Mb}$, far from the region colinear with wheat $5 \mathrm{D}$ centromere, which is delimited by markers $\operatorname{Os} 12 \mathrm{~g} 10540(5.58 \mathrm{Mb})$ and Os $12 g 08260$ (4.20 Mb) (Fig. 1). In summary, these results indicate that the wheat $5 \mathrm{D}$ centromere is at a different location than the centromeres of rice chromosome 12 and $B$. distachyon chromosome 4.
$V R N-D 4$ candidate region

TaVIL-DI has been previously suggested as a candidate for $V R N-D 4$ based on its centromeric location, homology with an Arabidopsis vernalization gene, and upregulation during vernalization ( $\mathrm{Fu}$ et al. 2007). Results from the highdensity map conclusively show that TaVIL-DI is not VRN$D 4$. Two independent recombination events were detected between the two loci, demonstrating that TaVIL-DI is proximal to $V R N-D 4$. Further supporting this conclusion, we found no polymorphism in the coding or regulatory regions of TaVIL-DI between wheat accessions differing in $V R N-D 4$. We are currently generating TILLING mutants of TaVIL1 to study its function in wheat.

To look for alternative candidate genes, we explored the VRN-D4 colinear region in $B$. distachyon (The International Brachypodium Initiative 2010). This species was selected among those with completely sequenced genomes based on its closer evolutionary relationship with wheat (Draper et al. 2001). The VRN-D4 colinear region in $B$. distachyon chromosome 4 is approximately $1-\mathrm{Mb}$ and includes a total of 127 predicted genes. Most of these genes have been annotated as structural or metabolic proteins and are unlikely candidates for $V R N-D 4$. However, ten genes in this region were annotated as transcription factors or are potentially involved in developmental processes (Table 3). A detailed analysis of these genes showed that only one B. distachyon gene (Bradi4g40350) has a wheat ortholog in the 5DS region completely linked to VRN-D4. This wheat gene, designated TaAGL31 is a MADS-box gene similar to Arabidopsis homeotic floral gene AGAMOUS. Since other MADS-box genes such as $V R N 1$ play important roles in the regulation of flowering (Chen and Dubcovsky 2012), we initially hypothesized that TaAGL31 might have played a similar role. However, no polymorphisms were detected in this gene between TDF-J and TDC carrying different $V R N-D 4$ alleles. In addition, no significant differences in TaAGL31 transcript levels were detected between TDF-J and TDC in the leaves of 3- and 5-week-old plants (Fig. 4). Although we cannot rule out the existence of polymorphisms outside the sequenced region or differences in expression at time points that were not tested, the current results provide little support to the hypothesis that TaAGL31 is a good candidate for $V R N-D 4$.

Although we cannot rule out the possibility that another gene present in the B. distachyon chromosome region colinear with the wheat $V R N-D 4$ candidate region is the true homolog of $V R N-D 4$, we favor the hypothesis that the $V R N-D 4$ gene originated in wheat after the divergence between wheat and $B$. distachyon. This hypothesis is supported by the lack of natural diversity for vernalization requirement in the wheat colinear centromeric regions on 
chromosomes 5AS and 5BS. In addition, the narrow geographical distribution of the dominant Vrn-D4 (Iwaki et al. 2000, 2001) argues in favor of a recent origin of this gene/ allele in hexaploid wheat.

\section{$V R N-D 4$ epistatic interactions}

In a previous study we showed that in wheat, the presence of the dominant Vrn-D4 allele in TDF-J was associated with a dramatic upregulation of VRN1 and VRN3 (=TaFT1) and downregulation of VRN2 transcript levels in the leaves (Yoshida et al. 2010). The activation of the positive feedback loop formed by these three genes (Fig. 5) results in the accumulation of VRN3 transcripts to very high levels (>tenfold ACTIN). The encoded TaFT1 protein is then transported to the shoot apical meristem where it induces VRN1 [and likely its paralogs FUL2 and FUL3, Chen and Dubcovsky (2012)] and initiates the transition from vegetative to reproductive stages.

Based on the previous expression results, we hypothesized that $V R N-D 4$ should be active in the leaves and should operate upstream (or be part) of the VRN1/VRN2/VRN3 positive feedback loop (Fig. 5). The epistatic interactions observed in this study support this model (Fig. 3). In the presence of dominant Vrnl alleles that eliminate or greatly reduce the need of vernalization to activate this positive feedback loop, the addition of $V r n-D 4$ has little additional effect on flowering time since its function in the leaves is redundant with that of VRNI. Similarly, when the dominant $V r n-B 3$ is present, the high levels of TaFT1 result in the upregulation of VRN1 and

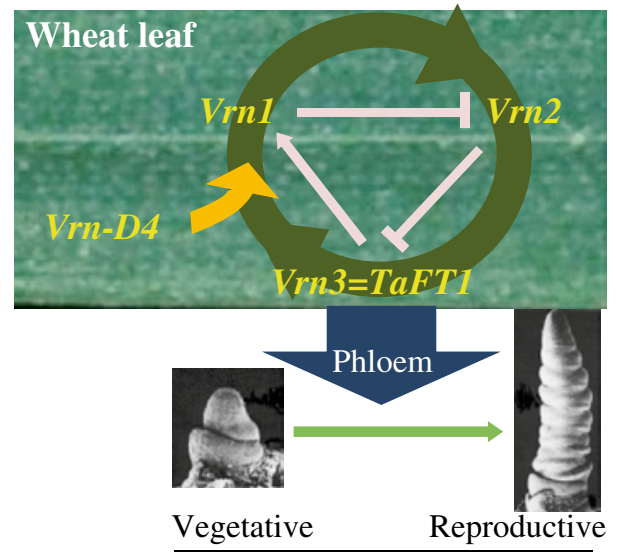

Shoot apical meristem

Fig. 5 Hypothetical model of $V R N-D 4$ role in the wheat leaves. According to this model $V R N-D 4$ activates the VRN1/VRN2/VRN3 positive feedback loop in the leaves, which results in an increase of VRN3 (=TaFT1). The TaFT1 protein is then transported through the phloem to the shoot apical meristem where it induces the meristemidentity genes and the initiation of the reproductive stage the downregulation of $V R N 2$, regardless of the presence of $V r n-D 4$. In wheat plants with a winter growth habit ( $v r n 1$, $V r n 2$, and $v r n 3$ allele combination) the positive feedback loop is not active. In this genetic background, the presence of the partially dominant Vrn-D4 is sufficient to activate the loop, resulting in significantly earlier heading time than in the winter lines (Fig. 3). Since changes in the transcription profiles of any of the genes in this feedback loop result in the alteration of the transcription profiles of the other two, we currently do not know which of these genes is the potential target of $V R N-D 4$.

To answer the previous question and to understand the molecular mechanisms involved in the VRN-D4 controlled reduction of the vernalization requirement, we are currently attempting to clone the $V R N-D 4$ gene. In addition to the answers to these basic questions, the cloning of $V R N-D 4$ may have practical implications. $V R N-D 4$ is an important contributor to natural variation in flowering time and adaptation to several regions in Asia and therefore, the identification of the gene responsible for these differences may provide a useful tool to develop better adapted wheat varieties for a changing environment.

Acknowledgments This project was supported by the National Research Initiative (Grants 2011-67013-30077 and 2011-6800230029) from the USDA National Institute of Food and Agriculture, by the Howard Hughes Medical Institute and the Gordon and Betty Moore Foundation grant GBMF3031, and Grant-in-Aids for Young Scientists (B) (23780005) from Japan Society for the Promotion of Science (JSPS). We are grateful to Dr. Takashi Matsumoto at NIAS in Tsukuba, Japan, for screening Chinese Spring BAC library and providing a positive clone including TaVIL-D1.

Open Access This article is distributed under the terms of the Creative Commons Attribution License which permits any use, distribution, and reproduction in any medium, provided the original author(s) and the source are credited.

\section{References}

Akhunov ED, Akhunova AR, Anderson OD, Anderson JA, Blake N, Clegg MT, Coleman-Derr D, Conley EJ, Crossman CC, Deal KR, Dubcovsky J, Gill BS, Gu YQ, Hadam J, Heo H, Huo N, Lazo GR, Luo MC, Ma YQ, Matthews DE, McGuire PE, Morrell PL, Qualset CO, Renfro J, Tabanao D, Talbert LE, Tian C, Toleno DM, Warburton ML, You FM, Zhang W, Dvorak J (2010) Nucleotide diversity maps reveal variation in diversity among wheat genomes and chromosomes. BMC Genomics 11:702

Allouis S, Moore G, Bellec A, Sharp R, Faivre Rampant P, Mortimer K, Pateyron S, Foote TN, Griffiths S, Caboche M, Chalhoub B (2003) Construction and characterisation of a hexaploid wheat (Triticum aestivum L.) BAC library from the reference germplasm 'Chinese Spring'. Cereal Res Commun 31: 331-338

Chen A, Dubcovsky J (2012) Wheat TILLING mutants show that the vernalization gene VRN1 down-regulates the flowering repressor $V R N 2$ in leaves but is not essential for flowering. PLoS Genet 8:e1003134 
Danyluk J, Kane NA, Breton G, Limin AE, Fowler DB, Sarhan F (2003) TaVRT-1, a putative transcription factor associated with vegetative to reproductive transition in cereals. Plant Physiol 132:1849-1860

Distelfeld A, Li C, Dubcovsky J (2009a) Regulation of flowering in temperate cereals. Curr Opin Plant Biol 12:178-184

Distelfeld A, Tranquilli G, Li C, Yan L, Dubcovsky J (2009b) Genetic and molecular characterization of the VRN2 loci in tetraploid wheat. Plant Physiol 149:245-257

Draper J, Mur LA, Jenkins G, Ghosh-Biswas GC, Bablak P, Hasterok R, Routledge AP (2001) Brachypodium distachyon. A new model system for functional genomics in grasses. Plant Physiol 127:1539-1555

Dubcovsky J, Dvorak J (2007) Genome plasticity a key factor in the success of polyploid wheat under domestication. Science 316:1862-1866

Dubcovsky J, Luo M, Dvorak J (1995) Differentiation between homoeologous chromosomes $1 \mathrm{~A}$ of wheat and $1 \mathrm{~A}^{\mathrm{m}}$ of Triticum monococcum and its recognition by the wheat $P h 1$ locus. Proc Natl Acad Sci USA 92:6645-6649

Dubcovsky J, Loukoianov A, Fu D, Valarik M, Sanchez A, Yan L (2006) Effect of photoperiod on the regulation of wheat vernalization genes VRN1 and VRN2. Plant Mol Biol 60:469-480

Endo TR, Gill BS (1996) The deletion stocks of common wheat. J Hered 87:295-307

Falconer DS (1960) Introduction to quantitative genetics. Oliver and Boyd, Edinburgh and London

Fu D, Szucs P, Yan L, Helguera M, Skinner JS, von Zitzewitz J, Hayes PM, Dubcovsky J (2005) Large deletions within the first intron in $V R N-1$ are associated with spring growth habit in barley and wheat. Mol Genet Genomics 273:54-65

Fu D, Dunbar M, Dubcovsky J (2007) Wheat VIN3-like PHD finger genes are up-regulated by vernalization. Mol Genet Genomics 277:301-313

Griffiths S, Sharp R, Foote TN, Bertin I, Wanous M, Reader S, Colas I, Moore G (2006) Molecular characterization of $P h 1$ as a major chromosome pairing locus in polyploid wheat. Nature 439:749-752

Hemming MN, Peacock WJ, Dennis ES, Trevaskis B (2008) Lowtemperature and daylength cues are integrated to regulate $F L O W$ ERING LOCUS T in barley. Plant Physiol 147:355-366

Hemming MN, Fieg S, Peacock WJ, Dennis ES, Trevaskis B (2009) Regions associated with repression of the barley (Hordeum vulgare) VERNALIZATION1 gene are not required for cold induction. Mol Genet Genomics 282:107-117

International Brachypodium Initiative (2010) Genome sequencing and analysis of the model grass Brachypodium distachyon. Nature 463:763-768

Iwaki K, Nakagawa K, Kuno H, Kato K (2000) Ecogeographical differentiation in east Asian wheat, revealed from the geographical variation of growth habit and $\mathrm{Vrn}$ genotype. Euphytica 111:137-143

Iwaki K, Haruna S, Niwa T, Kato K (2001) Adaptation and ecological differentiation in wheat with special reference to geographical variation of growth habit and Vrn genotype. Plant Breed 120:107-114

Jia J, Zhao S, Kong X, Li Y, Zhao G, He W, Appels R, Pfeifer M, Tao Y, Zhang X, Jing R, Zhang C, Ma Y, Gao L, Gao C, Spannagl M, Mayer KF, Li D, Pan S, Zheng F, Hu Q, Xia X, Li J, Liang Q, Chen J, Wicker T, Gou C, Kuang H, He G, Luo Y, Keller B, Xia Q, Lu P, Wang J, Zou H, Zhang R, Xu J, Gao J, Middleton C, Quan Z, Liu G, Wang J, Yang H, Liu X, He Z, Mao L, Wang J, International Wheat Genome Sequencing C (2013) Aegilops tauschii draft genome sequence reveals a gene repertoire for wheat adaptation. Nature 496:91-95

Kerber ER (1964) Wheat: reconstitution of the tetraploid component (AABB) of hexaploids. Science 143:253-255
Kerber ER, Rowland GG (1974) Origin of free threshing character in hexaploid wheat. Can J Genet Cytol 16:145-154

Krasileva KV, Buffalo V, Bailey P, Pearce S, Ayling S, Tabbita F, Soria M, Wang S, Consortium I, Akhunov E, Uauy C, Dubcovsky J (2013) Separating homeologs by phasing in the tetraploid wheat transcriptome. Genome Biol 14:R66

Li C, Dubcovsky J (2008) Wheat FT protein regulates VRNI transcription through interactions with FDL2. Plant J 55:543-554

Ling HQ, Zhao S, Liu D, Wang J, Sun H, Zhang C, Fan H, Li D, Dong L, Tao Y, Gao C, Wu H, Li Y, Cui Y, Guo X, Zheng S, Wang B, Yu K, Liang Q, Yang W, Lou X, Chen J, Feng M, Jian J, Zhang X, Luo G, Jiang Y, Liu J, Wang Z, Sha Y, Zhang B, Wu H, Tang D, Shen Q, Xue P, Zou S, Wang X, Liu X, Wang F, Yang Y, An X, Dong Z, Zhang K, Zhang X, Luo MC, Dvorak J, Tong Y, Wang J, Yang H, Li Z, Wang D, Zhang A, Wang J (2013) Draft genome of the wheat A-genome progenitor Triticum urartu. Nature 496:87-90

Linkiewicz AM, Qi LL, Gill BS, Ratnasiri A, Echalier B, Chao S, Lazo GR, Hummel DD, Anderson OD, Akhunov ED, Dvorak J, Pathan MS, Nguyen HT, Peng JH, Lapitan NL, Miftahudin, Gustafson JP, La Rota CM, Sorrells ME, Hossain KG, Kalavacharla V, Kianian SF, Sandhu D, Bondareva SN, Gill KS, Conley EJ, Anderson JA, Fenton RD, Close TJ, McGuire PE, Qualset CO, Dubcovsky J (2004) A 2500-locus bin map of wheat homoeologous group 5 provides insights on gene distribution and colinearity with rice. Genetics 168:665-676

Loukoianov A, Yan L, Blechl A, Sanchez A, Dubcovsky J (2005) Regulation of $V R N-1$ vernalization genes in normal and transgenic polyploid wheat. Plant Physiol 138:2364-2373

Lukaszewski AJ, Curtis CA (1993) Physical distribution of recombination in B-genome chromosomes of tetraploid wheat. Theor Appl Genet 86:121-127

Lukaszewski AJ, Gustafson JP (1983) Translocations and modifications of chromosomes in triticale $\mathrm{X}$ wheat hybrids. Theor Appl Genet 64:239-248

Luo MC, Gu YQ, You FM, Deal KR, Ma Y, Hu Y, Huo N, Wang Y, Wang J, Chen S, Jorgensen CM, Zhang Y, McGuire PE, Pasternak S, Stein JC, Ware D, Kramer M, McCombie WR, Kianian SF, Martis MM, Mayer KF, Sehgal SK, Li W, Gill BS, Bevan MW, Simkova H, Dolezel J, Weining S, Lazo GR, Anderson OD, Dvorak J (2013) A 4-gigabase physical map unlocks the structure and evolution of the complex genome of Aegilops tauschii, the wheat D-genome progenitor. Proc Natl Acad Sci USA. doi:10.10 73/pnas. 1219082110

Murray MG, Thompson WF (1980) Rapid isolation of high molecular weight plant DNA. Nucl Acids Res 8:4321-4325

Nitcher R, Distelfeld A, Tan C, Yan L, Dubcovsky J (2013) Increased copy number at the $H v F T 1$ locus is associated with accelerated flowering time in barley. Mol Genet Genomics 288:261-275

O'Brien L, Morell M, Wrigley C, Appels R (2001) Genetic pool of Australian wheats. In: Bonjean AP, Angus WJ (eds) The world wheat book. Lavoisier, Paris, pp 611-648

Paterson AH, Bowers JE, Chapman BA (2004) Ancient polyploidization predating divergence of the cereals, and its consequences for comparative genomics. Proc Natl Acad Sci USA 101:9903-9908

Pugsley AT (1972) Additional genes inhibiting winter habit in wheat. Euphytica 21:547-552

Qi L, Friebe B, Wu J, Gu Y, Qian C, Gill BS (2010) The compact Brachypodium genome conserves centromeric regions of a common ancestor with wheat and rice. Funct Integr Genomic 10:477-492

Sears ER, Sears LMS (1979) The telocentric chromosomes of common wheat. In: Ramanujam S (ed) Proceedings of the 5th international wheat genetics symposium. New Delhi, India, pp 389-407

Sung SB, Schmitz RJ, Amasino RM (2006) A PHD finger protein involved in both the vernalization and photoperiod pathways in Arabidopsis. Gene Dev 20:3244-3248 
Trevaskis B, Bagnall DJ, Ellis MH, Peacock WJ, Dennis ES (2003) MADS box genes control vernalization-induced flowering in cereals. Proc Natl Acad Sci USA 100:13099-13104

Uauy C, Distelfeld A, Fahima T, Blechl A, Dubcovsky J (2006) A NAC gene regulating senescence improves grain protein, zinc, and iron content in wheat. Science 314:1298-1301

von Zitzewitz J, Szucs P, Dubcovsky J, Yan L, Francia E, Pecchioni N, Casas A, Chen TH, Hayes PM, Skinner JS (2005) Molecular and structural characterization of barley vernalization genes. Plant Mol Biol 59:449-467

Wigge PA, Kim MC, Jaeger KE, Busch W, Schmid M, Lohmann JU, Weigel D (2005) Integration of spatial and temporal information during floral induction in Arabidopsis. Science 309: 1056-1059

Wu J, Kurata N, Tanoue H, Shimokawa T, Umehara Y, Yano M, Sasaki $\mathrm{T}$ (1998) Physical mapping of duplicated genomic regions of two chromosome ends in rice. Genetics 150:1595-1603

Xue W, Xing Y, Weng X, Zhao Y, Tang W, Wang L, Zhou H, Yu S, Xu C, Li X, Zhang Q (2008) Natural variation in Ghd7 is an important regulator of heading date and yield potential in rice. Nat Genet 40:761-767
Yan L, Loukoianov A, Tranquilli G, Helguera M, Fahima T, Dubcovsky J (2003) Positional cloning of the wheat vernalization gene VRN1. Proc Natl Acad Sci USA 100:6263-6268

Yan L, Loukoianov A, Blechl A, Tranquilli G, Ramakrishna W, SanMiguel P, Bennetzen JL, Echenique V, Dubcovsky J (2004a) The wheat $V R N 2$ gene is a flowering repressor down-regulated by vernalization. Science 303:1640-1644

Yan L, Helguera M, Kato K, Fukuyama S, Sherman J, Dubcovsky J (2004b) Allelic variation at the $V R N-1$ promoter region in polyploid wheat. Theor Appl Genet 109:1677-1686

Yan L, Fu D, Li C, Blechl A, Tranquilli G, Bonafede M, Sanchez A, Valarik M, Yasuda S, Dubcovsky J (2006) The wheat and barley vernalization gene VRN3 is an orthologue of FT. Proc Natl Acad Sci USA 103:19581-19586

Yoshida T, Nishida H, Zhu J, Nitcher R, Distelfeld A, Akashi Y, Kato $\mathrm{K}$, Dubcovsky J (2010) Vrn-D4 is a vernalization gene located on the centromeric region of chromosome $5 \mathrm{D}$ in hexaploid wheat. Theor Appl Genet 120:543-552

Yousafzai FK, Al-Kaff N, Moore G (2010) The molecular features of chromosome pairing at meiosis: the polyploid challenge using wheat as a reference. Funct Integr Genomic 10:147-156 